\title{
Acid Catalysed Isomerization of Nimbin to Isonimbin
}

\author{
S. Narasimhan ${ }^{1, *}$, R. Mohankumar ${ }^{1}$, V. P. Santhanakrishnan ${ }^{2}$, V. Radhakrishnan ${ }^{1}$ \\ ${ }^{1}$ Asthagiri Herbal Research Foundation, 162A-Perungudi Industrial Estate, Perungudi, Chennai-600096 \\ ${ }^{2}$ Department of Biotechnology, Centre for Plant Molecular Biology \& Biotechnology, Tamil Nadu Agricultural University, Coimba- \\ tore-641003
}

\begin{abstract}
The tetranortriterpenoid, nimbin contains the olefinic double bond at the ring C. When Ritter reaction was performed on this compound to introduce the amide moiety in ring $\mathrm{C}$ using sulfuric acid in acetonitrile, unexpectedly it underwent isomerization with the formation of isonimbin.
\end{abstract}

Keywords Nimbin, Isonimbin, Acetonitrile, Sulphuric Acid, Neemoil

\section{Introduction}

Nimbin, a C-seco limonoid of biological significance present in the seed oil of Azadirachta indica A.juss ${ }^{1,2}$. has got diversified functional groups in the structure and has shown substantial promise in insect control $^{3,4}$. Literature reports that photo-oxidised products of this compound showed a marked increase in the antifeedant activity than compared to the parent compound ${ }^{5,6}$ which gave impetus for performing the semi synthetic modification of the compound to introduce the nitrogen functionality through $\mathrm{C}-\mathrm{N}$ bond formation. Hence Ritter reaction ${ }^{7-10}$ was attempted to introduce the amide group across the olefinic double bound in ring $\mathrm{C}$ in nimbin.

Thus nimbin treated with acetonitrile in sulfuric acid at $0^{0} \mathrm{C}$ resulted in the formation of the product whose ${ }^{1} \mathrm{H}-\mathrm{NMR}$ and ${ }^{13} \mathrm{C}$-NMR does not contain the peak corresponding to the amide moiety and the number of the carbons in both the starting material and the product remained the same indicating a rearrangement reaction rather than the Ritter reaction.

\section{Results and Discussion}

A comparative analysis of the ${ }^{1} \mathrm{H} \&{ }^{13} \mathrm{C}$ NMR spectra (Figure.4.3a \& 4.3b) of the substrate ${ }^{11}$ and product revealed the characteristic signals corresponding to enone $(6.34 \&$ $5.85 \mathrm{ppm}$ in ${ }^{1} \mathrm{H}$ NMR \& $147.59 \& 125.99 \mathrm{ppm}$ in ${ }^{13} \mathrm{C}$ NMR), furan ring $\left(7.32,6.45 \& 7.59 \mathrm{ppm}\right.$ in ${ }^{1} \mathrm{H}$ NMR \& 119.19 , $109.35,139.52 \& 142.47 \mathrm{ppm}$ in ${ }^{13} \mathrm{C}$ NMR). The basic skeleton of the product is same as in the substrate except for changes in the D-ring.

The DEPT-135 spectrum of the compound showed 30

* Corresponding author:

asthagiri.herbal@gmail.com(S. Narasimhan)

Published online at http://journal.sapub.org/ajoc

Copyright (C) 2011 Scientific \& Academic Publishing. All Rights Reserved carbon signals, which are the same as in the starting material. The 30 carbons consisted of 10 quaternary, 11 methine, 2 methylene and 7 methyl. The functional groups like enone, ester and acetate were intact. The number of quaternary, methylene, methine and methyl carbons remain unaltered. But the oxygenated carbon signal at $86.97 \mathrm{ppm}$ corresponding to $\mathrm{C}-15$ is shifted from a methine environment to quaternary carbon, which is also evident from the disappearance of ${ }^{1} \mathrm{H}$ NMR signal at $5.57 \mathrm{ppm}$ corresponding to $\mathrm{H}-15$. This suggested a probable D-ring opening and closure. This has resulted in a similar rearrangement ${ }^{12}$ observed in few other limonoids such as nimbolide, salannin etc. There is a shift in C-13 signal from 135.01 to $94.83 \mathrm{ppm}, \mathrm{C}-14$ signal from 145.98 to $55.91 \mathrm{ppm}, \mathrm{C}-15$ from 86.97 to $31.29 \mathrm{ppm}, \mathrm{C}-16$ from 41.46 to $126.20 \mathrm{ppm}$ and $\mathrm{C}-17$ from 49.33 to $137.09 \mathrm{ppm}$. The new signal at $94.83 \mathrm{ppm}$ can be attributed to the oxygen-linked carbon. The rearrangement has resulted in appearance of multiplets at 2.34 and $5.74 \mathrm{ppm}$ corresponding to the H-15 \& H-16, which originally appeared at 5.57 and $2.19 \mathrm{ppm}$ in the substrate. From the above discussion it is evident that there exists a possibility of double bond isomerization. The structure of the product is given in the Scheme 1. Isonimbin has a molecular formula $\left(\mathrm{C}_{30} \mathrm{H}_{36} \mathrm{O}_{9}\right)$. UV spectrum of the compound showed $\lambda_{\max }$ at $226 \mathrm{~nm}$. Melting point: $212-215^{\circ} \mathrm{C}$. A complete assignment of the proton and carbon signals in the spectrum of isonimbin is represented in the experimental session.

\section{Possible Mechanism for Rearrange- ment of Nimbin to Isonimbin}

Attempts to introduce C-N bond formation (Ritter reaction) resulted in novel rearranged product. The mechanism involves $\mathrm{H}^{+}$ion coordination with etheral oxygen of the $\mathrm{C}$-ring followed by cleavage resulting to form a more stable allyl carbocation at the $\mathrm{C}-13$ and deprotonation of $\mathrm{H}-17$ results in a diene. This diene undergoes a 1,5 sigmatropic shift of the 
hydrogen atom followed by protonation at the $\mathrm{C}-14$ position. This results in a stable allyl carbocation, at the $\mathrm{C}-13$ position and migration of the double bond between C-16 \& C-17. Successive intramolecular attack of the $\mathrm{H}^{+}$on the tertiary carbocation results in $180^{\circ}$ rotation of bond between C-8 \& C-14 and subsequent ring closure to produce the rearranged product with intact cyclic ether namely isonimbin.
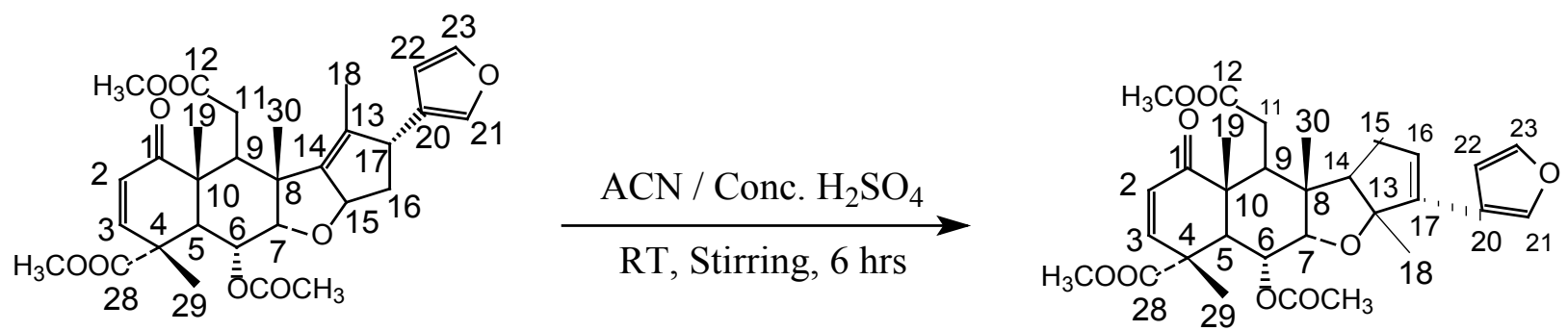

Scheme 1. Acid catalysed isomerization of the nimbin.<smiles>CC(=O)OC(C)=O</smiles>

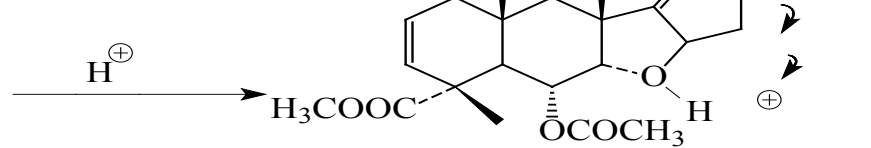

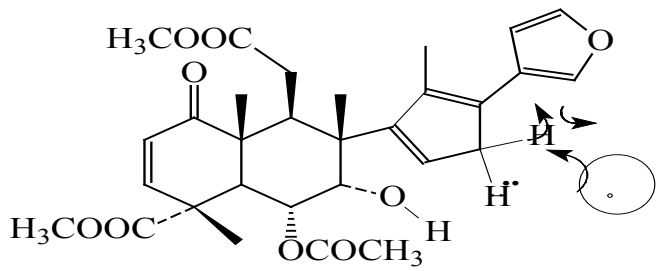

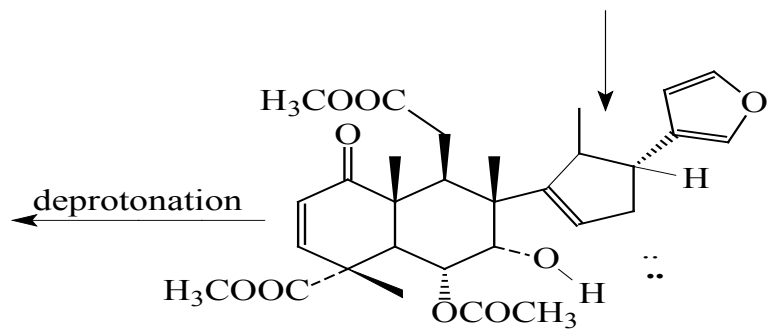

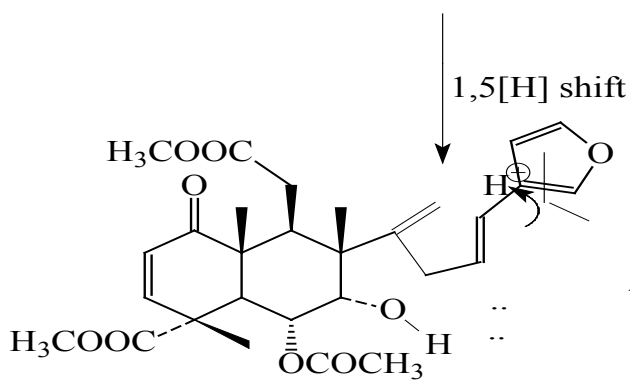

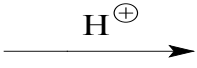

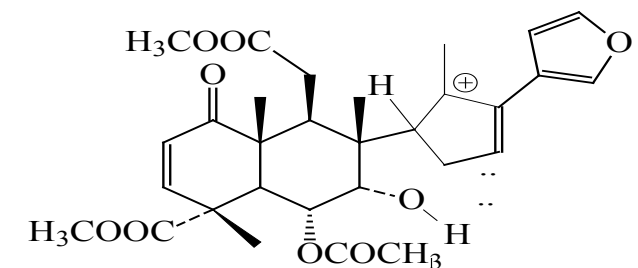

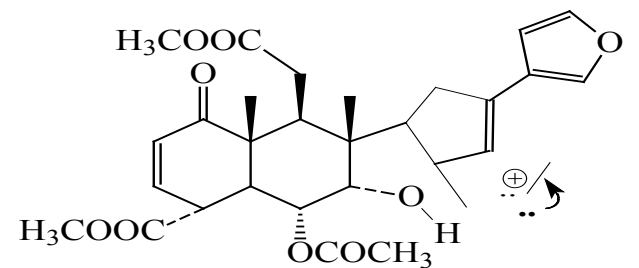

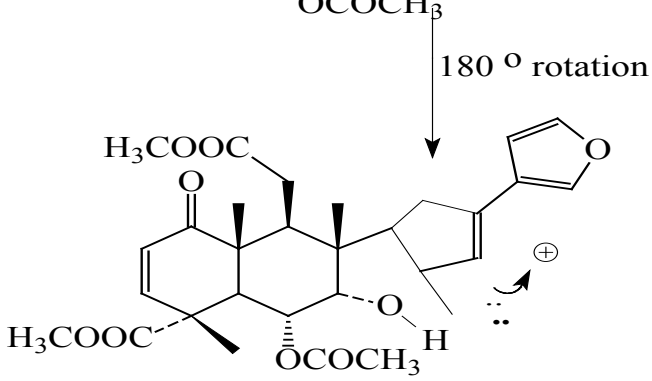

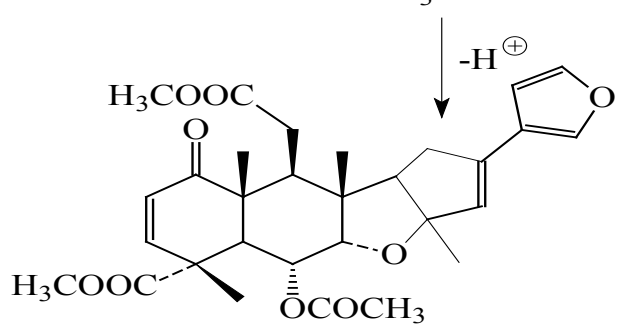

Isonimbin

Scheme 2. possible mechanism for the isomerization of Nimbin. 
Table 1. ${ }^{13} \mathbf{C}$ NMR data of Nimbin and Isonimbin ( $\delta$ in ppm) values in $\mathrm{CDCl}_{3 . .}$

\begin{tabular}{|c|c|c|}
\hline Carbon & Nimbin & Isonimbin \\
\hline 7 & 84.55 & 79.88 \\
\hline 13 & 135.07 & 94.83 \\
\hline 14 & 146.12 & 55.91 \\
\hline 15 & 87.08 & 31.29 \\
\hline 16 & 41.50 & 126.20 \\
\hline 17 & 49.46 & 137.09 \\
\hline 18 & 12.81 & 24.22 \\
\hline
\end{tabular}

\section{Experimental}

NMR spectrum was recorded on a Bruker $500 \mathrm{MHz}$ instrument using TMS as an internal standard and $\mathrm{CDCl} 3$ as the solvent. HPLC was performed on Shimadzu instrument with LC-10ATVP high pressure pump and C18 reverse phase Luna $5 \mathrm{u}$ column $(250 \times 4.60 \mathrm{~mm})$ and the peaks detected at $215 \mathrm{~nm}$ (SPD-10 AVP UV-VIS Detector) and the mobile phase being acetonitrile: water $(60: 40)$ at a flow rate of $0.5 \mathrm{ml} / \mathrm{min}$. Mass spectrum was recorded on a Shimadzu QP 1000A and QP 5000 mass spectrometer. Melting point was determined using a Raaga industries melting point apparatus and is uncorrected.

\subsection{Isolation of Nimbin}

Neem Oil (50g) was dissolved in methanol: water (60:40, $500 \mathrm{ml})$ and partitioned with chloroform $(200 \mathrm{ml} \times 3)$ and chloroform removed using rotary evaporator under vacuum. The above chloroform extract $(38 \mathrm{~g})$ was admixed with $80 \mathrm{~g}$ of silica gel (70-325 mesh), dried and admixture loaded in a column packed with silica gel using hexane as solvent. Initially the column was eluted with hexane followed by increasing order of polarity with ethylacetate and Nimbin eluted at 18\% ethylacetate in hexane and compared well with standard nimbin in TLC, the fraction with similar Rf were pooled and solvent removed to yield pure Nimbin $(680 \mathrm{mg}$, $0.014 \%)$.

\subsection{Modification of Nimbin to Isonimbin}

Nimbin $(0.5 \mathrm{mmol})$ was taken in a $100 \mathrm{ml}$ single necked round bottom flask fitted with guard tube, followed by $10 \mathrm{ml}$ of acetonitrile. The contents were cooled to $0^{\circ} \mathrm{C}$ and $0.5 \mathrm{ml}$ of concentrated sulphuric acid added slowly with stirring. The reaction was left to attain room temperature and additionally stirred for $6 \mathrm{hrs}$. The completion of the reaction was monitored by TLC. After completion, the flask was immersed in ice-bath and aqueous ammonia was added slowly untill the $\mathrm{pH}$ is $7-8$, the solution was concentrated under reduced pressure using rotary evaporator and poured into ice-cold water and extracted using ethyl acetate and the crude extract was purified using flash (under nitrogen) column chromatography and pure product eluted at 16\% Ethyl acetate in hexane (Isonimbin - Yield: 62\%).

\section{Supporting Information}

${ }^{1} \mathrm{H}$ NMR (500MHz, $\mathrm{CDCl}_{3}$ ): $\delta=0.96$ (s, 3H, H-30), 1.29 (s, 3H, H-29), 1.34 (s, 3H, H-19), 1.66 (s, 3H, H-18), 1.90 (s, $3 \mathrm{H}, \mathrm{OCOCH} 3), 2.13 \& 2.70$ (m, 2H, H-11a \& 11b), 2.34 (m, 2H, H-15), 2.50 (m, 1H, H-14), 2.70 (m, 1H, H-9), 3.50 (d, $1 \mathrm{H}, \mathrm{J}=3.0 \mathrm{~Hz}, \mathrm{H}-5), 3.76(\mathrm{~s}, 3 \mathrm{H},-\mathrm{COOCH} 3), 3.80(\mathrm{~d}, 1 \mathrm{H}, \mathrm{J}$ $=12.3 \mathrm{~Hz}, \mathrm{H}-7), 3.81(\mathrm{~s}, 3 \mathrm{H},-\mathrm{COOCH} 3), 5.19(\mathrm{dd}, 1 \mathrm{H}, \mathrm{J}=$ 3.0, $12.3 \mathrm{~Hz}, \mathrm{H}-6), 5.74(\mathrm{~m}, 1 \mathrm{H}, \mathrm{H}-16), 5.85(\mathrm{~d}, 1 \mathrm{H}, \mathrm{J}=$ $10.5 \mathrm{~Hz}, \mathrm{H}-2), 6.34(\mathrm{~d}, 1 \mathrm{H}, \mathrm{J}=10.4 \mathrm{~Hz}, \mathrm{H}-3), 6.45(\mathrm{~m}, 1 \mathrm{H}$, $\mathrm{H}-22), 7.32$ (m, 1H, H-21), 7.59 (m, 1H, H-23).

${ }^{13} \mathrm{C}$ NMR $\left(500 \mathrm{MHz}, \mathrm{CDCl}_{3}\right): \delta=16.67(\mathrm{C}-30), 16.96$ $\left(\mathrm{C}-19,17.1 \quad(\mathrm{C}-29), \quad 20.62 \quad\left(\mathrm{OCOCH}_{3}\right), 24.2 \quad\right.$ (C-18), 31.3(C-15), 33.2 (C-11), 41.3 (C-9), 42.3 (C-5), 47.0 (C-4),48.9 (C-10), 49.9 (C-8), $51.8 \quad\left(-\mathrm{COOCH}_{3}\right), 52.7$ $\left(-\mathrm{COOCH}_{3}\right), 55.9(\mathrm{C}-14), 68.3(\mathrm{C}-6), 79.9(\mathrm{C}-7), 94.8(\mathrm{C}-13)$, 109.4 (C-22), 119.2 (C-20), 126.0 (C-2), 126.2 (C-16), 137.1 (C-17), 139.5 (C-21), 142.5 (C-23), 147.6 (C-3), 170.3 $\left(\mathrm{OCOCH}_{3}\right), 174.9(\mathrm{C}-12), 174.9(\mathrm{C}-28), 201.8(\mathrm{C}-1)$.

\section{Conclusions}

Thus the attempts to introduce the nitrogen in nimbin by Ritter reaction has resulted in an unexpected rearranged product isonimbin.

\section{ACKNOWLEDGEMENTS}

RMK thanks DBT, VPS and VRK thank CSIR for funding support and Spic Science Foundation for the Analytical facility.

\section{REFERENCES}

[1] Gaikwad, B. R.; Mayilvaganan, T.; Vyas, B. A.; Bhat, S. V. Phytochemistry. 1990, 29, 3963-3965

[2] Gupta, S. S.; Mitra, C. R. J. Sci. Food. Agric. 1953, 4, 44-48

[3] Biswas, K.; Chattopadhyay, I.; Banerjee, R. K.; Bandyopadhyay, U. Current Science. 2002, 82, 1336-1345

[4] Champagne, D. E., Koul, O., Isman, M. B., Scudder, G. G. E.; Towers, G. H. N. Phytochemistry. 1992, 31, 377-394

[5] Simmons, M. S.; Jarvis A. P.; Johnson, S.; Jones, G. R.; Morgan, E. D. Pest Manag Sci. 2002, 60, 459-64

[6] Suresh, G.; Geetha ,G.; Daniel Wesley, S.; Pradeep Singh, N. D.; Malathi, R.; Rajan S. S. J. Agric. Food Chem. 2002, 50, $4484-4490$

[7] Ritter, J. J.; Minieri, P. P. J. Am. Chem. Soc. 1948, 70, 4045-4048

[8] Ritter, J. J. Murphy, F. X. J. Am. Chem. Soc. 1952, 74, 763-765

[9] Parris, C. L. Organic syntheses. Coll. 1973, 5, 73

[10] Ritter, J. J. Kalish, J. Organic syntheses. Coll. 1973, 5, 471 
[11] Johnson, S. Morgan, E. D. Journal of Chromatography A. [12] Anitha,G.; Josepha, L. R. J.; Narasimhan, S.; Anand Solomon, $1997,761,53-63$ K.; Rajan, S.S. Eur. J. Med. Chem. 2006, 41, 997-1002 